\title{
HISTORIA DE LA IGLESIA, CATOLICISMO SOCIAL Y PATRIMONIO CULTURAL Y ARTÍSTICO EN TIERRAS PALENTINAS, SEGÚN EL P. MANUEL REVUELTA
}

\author{
MIGUEL DE SANTIAGO RODRÍGUEZ ${ }^{1}$
}

\begin{abstract}
RESUMEN: En este artículo se hace un recorrido por distintos temas palentinos en los que insistió el profesor e historiador Manuel Revuelta; en concreto, sobre la historia de aquella Iglesia diocesana en los siglos XIX y XX, sobre el sindicalismo católico agrario liderado por el jesuita Sisinio Nevares y el seglar Antonio Monedero y sobre temas culturales, como las tres estancias de santa Teresa en Palencia y otras cuestiones relacionadas preferentemente con la historia y el patrimonio artístico de varios pueblos del Camino de Santiago a su paso por tierras palentinas.

Palabras Clave: Manuel Revuelta; historia de la Iglesia palentina; sindicalismo católico agrario; santa Teresa; Sisinio Nevares; Antonio Monedero; Camino de Santiago.
\end{abstract}

\section{History of the Church, social catholicism and cultural and artistic heritage in the lands of Palencia, according to Fr. Manuel Revuelta}

ABSTRACT: The present article presents a tour of different Palentine themes that Professor and historian Manuel Revuelta focused on. In particular, topics concerning the History of the diocesan Church in the nineteenth and twentieth centuries, the Catholic agrarian unionism led by the Jesuit Sisinio Nevares and the layman Antonio Monedero as well as cultural issues, such as the three stays of Saint Theresa in Palencia and other aspects mostly related to the History and artistic heritage of various villages on the Way of Saint James as it crosses the province of Palencia.

KEY Words: Manuel Revuelta; History of the Palentine Church; Agrarian Catholic Trade Unionism; St. Theresa; Sisinio Nevares; Antonio Monedero; Way of Saint James.

\footnotetext{
1 Académico de la Institución Tello Téllez de Meneses. Palencia. Correo electrónico: miguel.de.santiago@hotmail.com.
} 
Para comprender multitud de temas de la historia de la Iglesia de los últimos siglos es necesario acudir al ingente número de escritos del profesor e investigador jesuita Manuel Revuelta González (Población de Campos, Palencia, 1936 - Salamanca, 2019). Así sucede con el liberalismo español, las relaciones entre la Iglesia y el Estado, el confesionalismo en la vida sociopolítica, el anticlericalismo dominante en la sociedad española, la exclaustración de la Compañía de Jesús, sus colegios y la Restauración de la misma.

El conocimiento de la historia y la gran capacidad de análisis los puso también de manifiesto cuando abordó temas directamente relacionados con su tierra palentina: las estancias de santa Teresa de Jesús (siglo Xvi) y los avatares de aquella Iglesia diocesana desde la guerra de la Independencia a nuestros días, centrándose sobre todo en los momentos más interesantes, como los pontificados de Lozano Torreira y de Almaraz y Santos, y el surgimiento y esplendor de los sindicatos católicos agrarios que tuvieron su origen en Palencia gracias al papel desempeñado por el jesuita Sisinio Nevares y el laico Antonio Monedero; además, las exclaustraciones y desamortizaciones le dieron pie para tratar cuestiones relacionadas con el patrimonio cultural y artístico, fundamentalmente en torno al Camino de Santiago.

A la hora de internarse en estos campos de la historia le sirvió de mucho su pertenencia a la Institución Tello Téllez de Meneses, Academia Palentina de Historia, Letras y Bellas Artes, en la que ingresó como académico numerario en 1992, siendo uno de sus miembros más activos hasta el final de sus días.

\section{HISTORIA DE LA IGLESIA DE PALENCIA}

El profesor jesuita dibujó las peculiaridades históricas de la evolución vivida por la diócesis palentina en el siglo xIX y primera mitad del xx; en lo fundamental, nada diferente a lo que ocurría en otras diócesis españolas. Se vivió un periodo de crisis que abarca la primera mitad del siglo xIX y otro periodo de restauración.

Con gran claridad (Revuelta, 1984, 1992) va desgranando datos, causas y consecuencias de las tres primeras fases de la revolución liberal: $1^{\mathrm{a}}$, la guerra de la Independencia, con las reformas religiosas propiciadas por el rey José y las secuelas de profanaciones y saqueos en algunas parroquias de la diócesis, prohibiciones de conferir órdenes sagradas, exigencia de juramento de fidelidad de los sacerdotes al rey intruso, supresión de conventos de religiosos e incautación de sus bienes por lo que quedaron abandonados a 
la ruina y la rapiña; $2^{\mathrm{a}}$, el trienio constitucional, con la vuelta de los liberales al poder y la implantación de reformas eclesiásticas y la repetida supresión y reforma de conventos además de la venta de sus bienes (fue una época de miseria del clero, trasiego de frailes, monjes exclaustrados, desbandada propiciada por las secularizaciones, capitalistas sin escrúpulos lanzados a hacerse con las fincas eclesiásticas, todo lo cual golpeó el sentimiento de los católicos palentinos); y $3^{\mathrm{a}}$, la desarticulación definitiva de la Iglesia antigua durante la minoría de Isabel II, que también está marcada por los horrores de la guerra civil, las algaradas callejeras y la revolución liberal, así como la descontrolada desamortización de las posesiones eclesiásticas llevada a cabo por Mendizábal (todos los conventos fueron cerrados, los edificios y su patrimonio artístico y cultural subastados, los bienes incautados).

El caso palentino reviste algunas peculiaridades (Revuelta, 2008). Por ejemplo, vemos cómo durante el alzamiento español contra Napoleón se formó una Junta de Armamento y Defensa y el obispo Francisco Javier Almonacid dispuso que se alistaran los clérigos ordenados de menores, permitió que lo hicieran los sacerdotes y animó a los fieles a defender la Religión y la Patria. Destaca también su actuación cuando, en medio de los desastres de la guerra, no abandonó a su grey sino que compartió tribulaciones con ella, trató de mantener la paz en el clero y actuó de mediador ante los generales franceses, si bien luego no se mostraría compasivo al desaconsejar la amnistía general que Fernando VII pensaba otorgar a los afrancesados... Palencia tuvo una actitud de sumisión pasiva al dominio francés, pues era imposible hablar en contra del régimen josefino, había además un obispo pacifista, que, pese a apoyar el levantamiento contra los franceses, luego actuó de mediador y, por tanto, se imponía el disimulo y aceptación de los hechos a la espera de tiempos mejores.

La guerra de la Independencia no fue una guerra de religión, pero la religión fue un elemento aglutinante y unitivo de todo el pueblo a la hora de defender una identidad, tradiciones, bienes y valores que se veían amenazados, sentimiento de dignidad ofendida y rechazo de una injusticia. Fueron terribles los asaltos a las iglesias de Torquemada y de Aguilar de Campoo, junto a otros abusos, rapiñas y asesinatos perpetrados contra la población civil.

La figura del obispo Almonacid le merece al historiador jesuita P. Revuelta un juicio benevolente. Como la mayoría del clero diocesano y de los fieles practicaron un «afrancesamiento pasivo, más por necesidad que por convicción» (Revuelta, 2008, p. 174), el obispo optó por acomodarse a las circunstancias buscando bienes mayores que la fidelidad a uno u otro rey: el mayor bien de sus diocesanos y el mantenimiento de la religión. Al obispo le pareció que la resistencia era inútil y podía resultar desastrosa para 
el pueblo. Y se mostró cauto, prudente y pragmático: supo someterse a los franceses sin humillación, sin cometer la imprudencia de escribir pastorales comprometidas. Así las cosas, nadando entre dos aguas y cambiando de bando según las circunstancias, consiguió que Palencia, al contrario que Burgos, se librara de los desastres de la guerra. Una vez concluida, los palentinos, con su obispo y clero al frente, expresaron su júbilo por la derrota de los franceses y el retorno del rey Fernando; se sucedieron las misas de acción de gracias, Te Deum, repique de campanas, como se había hecho antes en honor del rey José. Pero esta vez las manifestaciones de religiosidad se celebraban con total sinceridad.

Otros momentos posteriores de la historia de la Iglesia palentina fueron estudiados por Manuel Revuelta en las conferencias pronunciadas en los tres Congresos de historia de Palencia, entre los años 1987 y 1995. La plenitud de la restauración religiosa tendría lugar durante los pontificados fecundos de dos excelentes obispos de la diócesis, como Juan Lozano Torreira, un gran intelectual y prelado de los pobres, y Enrique Almaraz Santos. Es la época de La Propaganda Católica, fundada por el canónigo José Madrid y Manso a comienzos de 1869, la difusión de la buena prensa, los círculos católicos de obreros, las escuelas nocturnas para adultos, la catequesis, el restablecimiento de varias comunidades de religiosos, algunas de vida activa, las obras de beneficencia que causaron sensación en tiempos de incuria social, en suma, una época de renovación de la vida cristiana, muy activa, renovadora y estimulante.

Para contar los años del largo pontificado de Lozazo Torreira (1866-1891), un intelectual y profesor universitario, nuestro historiador se vale de los informes realizados con ocasión de sus visitas ad limina en 1870 y en 1882 (Revuelta, 1987). Este gallego sencillo, tímido, culto y devoto, empleó su dinero en instituciones benéficas y fue muy querido de sus fieles. Vivió unos años agitados por las crisis impuestas a las iglesias por las revoluciones liberales y el desafío de las nuevas ideologías. En la primera relación de la visita ad limina de 1870 recoge la pugna con los derechos de la religión católica tradicional y en la de 1882, por el contrario, un ambiente pacífico y de recuperación espiritual; en ambos casos aparecen las repercusiones que tienen en el comportamiento de los palentinos en aquellos momentos tan decisivos. Encontramos en los informes ad limina apuntes sobre la situación de miseria y desamparo y sobre las sospechas y recelos infundados hacia el clero, generados por el ambiente y espíritu de la revolución. Y esto traía, como consecuencia, hurtos y expolios en los templos, aunque no supuso alteraciones en los servicios religiosos por parte de un clero obediente ni en la fe del pueblo fiel. Así se explica que empezaran a aflorar asociaciones de seglares 
con una exigente espiritualidad que se dedicaban a la propaganda y caridad. En el informe de 1882 el obispo apunta algunas rectificaciones de la política religiosa canovista con favorables consecuencias en el clero, las comunidades religiosas, los colegios, las instituciones caritativas, las misiones populares.

Al trazar la semblanza del obispo Almaraz (Revuelta, 1990), el historiador lo define escuetamente: un buen obispo para una diócesis tranquila y pacífica. Destacó por su labor doctrinal (escritos pastorales, predicación) y tomó muy en serio su obligación de maestro de la fe. Como siempre, el P. Revuelta contextualiza el periodo a analizar y así se detiene a exponer las grandes líneas de los papas de ese momento, León XIII y Pío X, el primero caracterizado por su apertura al mundo y el segundo por su postura defensiva de la fe, y el momento vivido por la Iglesia de España, entre la restauración y el anticlericalismo. Es un momento de crisis económica, grave crisis agraria en Palencia, que trajo miseria, paro, emigración de muchas familias obreras... Ante una rutina conformista, los responsables de la Iglesia procuraron animar la fe personal encauzándola en acciones sociales que redundasen en beneficio de la sociedad, con atención especial a los sectores más desamparados.

La época del reinado de Alfonso XIII prácticamente coincide con las tres primeras décadas del siglo xx. El pueblo palentino, con un clero activo y apreciado, se organiza y adquieren relevancia los movimientos católicos seglares, los cuales tienen impacto en la sociedad, con una especial referencia a los sindicatos católicos agrarios. Ciertamente la Iglesia estuvo muy presente en la sociedad palentina, mayoritariamente campesina y muy ligada a las tradiciones y sentimientos religiosos (Revuelta, 1995).

El advenimiento de la Segunda República inquietó a los sectores eclesiásticos. El cambio de régimen preocupaba, pero la reacción del obispo Agustín Parrado fue serena, sensata y democrática: acatar los poderes constituidos, cooperar al bien común, mandar a los sacerdotes que no se mezclasen en política y respetasen a las autoridades y colaborasen con ellas en los fines nobles...

El análisis del historiador jesuita respecto a este segundo periodo de restauración lo concentra en torno a los factores favorables a la restauración religiosa, tales como el ambiente de renovación cristiana después de los años de crisis, que venía favorecido por factores ambientales (el movimiento de renovación espiritual y de restauración eclesiástica), por el factor humano (el hondo sentido tradicional y religioso del pueblo palentino) y el organizativo (el buen gobierno de los obispos y la eficacia de sus colaboradores). Se vive en aquella sociedad rural, tradicional y patriarcal de la pequeña provincia un fervor espiritual y entusiasmo doctrinal y surgen las organizaciones de 
obras apostólicas, siguiendo la línea del magisterio social de la Iglesia. Ese catolicismo restaurador que representa una especie de reconquista cristiana de la cuestión social, del mundo de la cultura, de la prensa y de la educación contó con fuerte oposición anticlerical, pero logró grandes éxitos, apoyado por la religiosidad de las gentes. En unas familias profundamente cristianas y fervorosas sin fanatismo y con dificultades socioeconómicas para ascender socialmente y encontrar un modo de vida nada extraña que surja un clero abundante, sacrificado y fiel. Pese a la relativamente escasa población, la Iglesia palentina cuenta en esos momentos con numerosas escuelas apostólicas y seminarios. Y también con buenos obispos, un clero pacífico, comunidades religiosas obedientes y grupos de seglares católicos, que fueron excelentes colaboradores en tareas de predicación y misiones populares, asistencia social en hospitales y asilos, enseñanza para las clases proletarias, acción social en el mundo agrario.

\section{CATOLICISMO SOCIAL}

Otro bloque temático que aparece en los trabajos de investigación del historiador Manuel Revuelta es el del catolicismo social que tuvo gran protagonismo en la diócesis de Palencia, como acabamos de apuntar. Dedicó también varios trabajos a las figuras del jesuita carrionés Sisinio Nevares (Carrión de los Condes, Palencia, 1878 - Valladolid, 1946), gran promotor del sindicalismo agrario católico, y del agricultor seglar de Dueñas Antonio Monedero (Dueñas, 1872-1940). Y es que, en la historia del sindicalismo agrario, Palencia tuvo la iniciativa y alcanzó relevancia nacional (Revuelta, 2010, pp. 141-189).

El obispo Almaraz quería ver los templos llenos y pensaba sinceramente que la ausencia de fieles en ellos era síntoma de la pérdida de fe que acarreaba grandes males. Pero al mismo tiempo estaba cada vez más convencido de que la regeneración cristiana de la sociedad se jugaba en la prensa, en las asociaciones, en la creación de sindicatos, cajas de ahorro y toda clase de obras benéficas y sociales. Y tan convencido estaba de ello que incitaba a los sacerdotes a salir de la sacristía para emprender la acción social. Tiene varios escritos pastorales sobre esta cuestión, pero destaca uno de 1902 en el que insiste en el deseo del papa León XIII de mejorar la situación moral y material del obrero.

El obispo convirtió La Propaganda Católica en obra diocesana secundando los deseos del fundador, que veía así asegurada la continuidad y 
protección de su obra, la instaló en el palacio episcopal y pidió a los sacerdotes y seglares, patronos y obreros, que colaboraran. Desarrolló una tarea muy importante, mediante las actividades y enseñanzas orales y escritas de un grupo de sacerdotes sociales: los canónigos Gregorio Amor, Eugenio Madrigal y Anacleto Orejón y algunos párrocos como Ildefonso Arroyo, Valentín Gómez, Gerardo Castillo, Eugenio Mediavilla. Todos fomentaron la formación de círculos obreros y luego la sindicación agraria, que logró implantarse en numerosos pueblos, al contrario de lo que ocurría en las provincias limítrofes. Los sindicatos católicos agrarios fueron un poderoso instrumento de acción de la Iglesia en la sociedad rural palentina. Y, aunque se declaraban ajenos a la política, ciertamente iban configurando una masa de campesinos que se adhiriera a posiciones políticas conservadoras para servir de alternativa al liberalismo y al socialismo.

No expresa el P. Revuelta un juicio contundente de lo que supuso la sindicación agraria; entiende que no resulta fácil hacerlo porque fue un fenómeno complejo en el que concurrieron muchas circunstancias, inspiraciones e intereses. Y porque hubo de todo: asistencia a favor del campesino, respuesta a los problemas del agro castellano, actitudes neutralizadoras ante la amenaza de las reivindicaciones revolucionarias, instrumentalización del control social de la oligarquía para someter al campesinado a sus intereses.

Las personalidades del P. Nevares y de Antonio Monedero han sido suficientemente estudiadas por nuestro historiador en varios escritos. Y merecen ser leídos con detenimiento para comprender la relevancia que ambos tuvieron en un momento concreto de la historia de España y de la historia de la Iglesia. No hay espacio aquí para extenderse en ello.

La vocación sindical de Monedero vino propiciada por su encuentro con el padre jesuita Antonio Vicent, primero epistolar y después en persona. Pero el agricultor ya venía practicando obras sociales en su propia finca de «El Aguachal»:

Como tenía mucha dependencia había establecido para toda ella una ligera organización social, compuesta de socorros mutuos para casos de enfermedad y cooperativa de consumos, completada con una escuela para sus niños, en la que uno de los administradores y yo éramos sus maestros. (Monedero, 1921, p. 14)

Un hito en la historia del sindicalismo agrario lo constituye el grandioso mitin agrario del 5 de mayo de 1912 en la plaza de toros de la capital palentina, convocado por Ángel Herrera, director de la Acción Católica Nacional de Jóvenes Propagandistas y director de El Debate; éste fue quien puso en relación a los dos palentinos, Nevares y Monedero, que hasta entonces no se conocían. A partir de ese instante el agricultor se dedica definitivamente a la 
acción social y comienza una campaña triunfal por los pueblos palentinos; se invocaba el regeneracionismo, se hacía una protesta política, se alentaba el deseo de mejoras económicas. Otro hito del sindicalismo es la unión de los sindicatos dispersos en la Federación Católica Agraria de Palencia, que se formalizó el 26 de marzo del año siguiente y sería pionera, modelo y referente en toda España; además fue conocida en todo el país por las crónicas que aparecían en el periódico El Debate, muchas de ellas firmadas por «Juan Hidalgo», pseudónimo que utilizaba Antonio Monedero.

Tenía el título de doctor en Derecho por la Universidad de Valladolid. Y escribió varios libros sobre temas agropecuarios con habilidad literaria y grandes dotes pedagógicas. Dedicó su vida a fundar, organizar, dirigir y propagar de palabra y por escrito los sindicatos católicos en el campo español. Su fe cristiana lo llevó a ser apóstol social, una especie de misionero seglar, por los pueblos de España predicando las excelencias del sindicalismo cristiano. Veía los problemas del campo y la necesidad de reformas sociales, pero alejadas de posiciones ideológicas totalizantes. Estaba tan lejos del liberalismo clásico, causante del agravamiento del problema de la tierra con las desamortizaciones y la inhibición social de la ley de la oferta y la demanda, como del socialismo y sus derivaciones comunista y anarquista por la aplicación de la revolución y la lucha de clases para abolir la propiedad. El sindicalismo católico agrario defendía la propiedad y la armonía y solidaridad de las clases sociales, pero sin excluir reformas estructurales basadas en la justicia y la caridad. Es, pues, una posición antiliberal, antisocialista, confesional, inspirada en la doctrina social de la Iglesia y que podía desembocar en un sistema de representación popular o democracia cristiana.

En 1913 le sobrevinieron las desgracias: en enero se le quemó la casa, en junio se le apedreó gran parte de la cosecha y en octubre se rompió la turbina de su fábrica de luz. Un hombre cristiano como él lo interpretó como una llamada de Dios, arrendó sus fincas y se dedicó por entero a la propaganda y organización sindical:

¿Era el Señor que me llamaba, por tan extraordinario modo, al despego de las cosas propias, para que me ocupara con más desembarazo de las suyas? Yo así hube de entenderlo, y creyendo interpretar su divina voluntad, arrendé mis fincas y me dediqué en cuerpo y alma a la propaganda y organización de la sindicación católica agraria. (Ibíd, p. 20)

En 1919, durante seis meses fue director general de Agricultura en el Ministerio de Fomento; intentó hacer una reforma agraria moderada, que establecía expropiaciones de fincas abandonadas o mal explotadas y facilitaba repartos y arrendamientos favorables a los campesinos más pobres y a los obreros del campo, presencia de los obreros en la dirección de los sindicatos 
para limitar la preeminencia patronal... Buscaba, sobre todo, las mejoras sociales antes que las ventajas mercantilistas.

Dos años después tuvo que dejar la presidencia de la Confederación Nacional Católico Agraria (CNCA); le supuso un gran dolor, que asumió con resignación cristiana y un cierto desengaño. Al sentirse relegado por la CNCA, volvió a peregrinar por pueblos y aldeas tratando de poner en marcha nuevas organizaciones: la Unión Católico-Social de España para infundir el ideal espiritual que no logró meter en la CNCA y la Liga Nacional de Campesinos, unos sindicatos católicos sin federaciones dedicados a favorecer a los pequeños y medianos campesinos, arrendatarios y jornaleros.

Era frecuente que acudieran el P. Nevares y Monedero, acompañados por algún propagandista joven; todos ellos dotados de gran facilidad de palabra, oratoria fogosa y sugestiva, con dotes para conectar con las masas sencillas de los pueblos. Los actos estaban perfectamente preparados: los itinerarios y actividades fijados de antemano. Viajan hasta allí en tren, luego en coches de línea, en carros o en caballerías. Eran recibidos con cohetes, salvas y volteo de campanas, mientras los campesinos continuaban llegando como en peregrinación o romería. Los párrocos eran piezas esenciales. Había colaboradores seglares, profesionales y benéficos propietarios influyentes. Los propagandistas asistían a la misa dominical y comulgaban. Luego hablaban al aire libre, en las plazas, en las eras, en los atrios de las iglesias, sobre tribunas o desde los balcones, en teatros, escuelas, templos. La propaganda oral era imprescindible, pues, si la población no era analfabeta, difícilmente tenía acceso a la lectura. Las gentes los escuchaban embelesados cuando hacían una radiografía de los males que sufría el campesinado, los minifundios, los latifundios, los desaciertos de la política agraria, la ignorancia a la que se los reducía, la irresponsabilidad moral de usureros (se llegaba a pedir a los labradores un interés del 80 por ciento), el abandono de los políticos, las burlas de los gobiernos, el egoísmo de todos ellos, la necesidad de una vida moral y religiosa, la necesidad de cajas rurales que estropeen el negocio de tantas alimañas y chupasangres, la demanda de ajuste de los precios con las subidas de los costes de producción. Los jóvenes propagandistas facilitados por Ángel Herrera entusiasmaban con su elocuencia a las gentes y preparaban los ánimos desde el inicio. Luego el P. Nevares, que había predicado en la misa con su oratoria persuasiva, volvía a dirigirse al pueblo hablando de las ventajas del sindicalismo y del funcionamiento de las cajas rurales y cooperativas. Monedero, como técnico agrícola, explicaba también la mejora de las explotaciones agrícolas y ganaderas, sin olvidar el mensaje religioso. Antonio Monedero censura a los ricos insolidarios que se acercan al sindicato para comprar abonos pero no para conceder préstamos, a los caciques 
que quieren medrar en la política prometiendo el oro y el moro a los pobres labradores en tiempos de elecciones, a los terratenientes inmovilistas con explotaciones injustas que provocan el avance del socialismo y el anarquismo. Por eso veía en los sindicatos católicos la panacea de todos los males y para desterrar la sensación de vacío y desamparo que tenían los agricultores. Mantenía que los principios básicos de la confederación sindical debían acentuar la espiritualidad, religión, familia, propiedad, democracia cristiana, inclinación preferente a los más pobres, sindicato mixto de patronos, colonos y obreros como más adecuado a la clase agrícola, creación de pequeños propietarios y alejamiento de la política.

Todos los avatares y afanes en que se involucró este labrador con buena posición económica, nada caciquil y sin arribismo político, aunque tuviera sus convicciones, solamente se explican por su fe y vivencia profundamente católica y su consecuente compromiso social en defensa de las gentes del campo que tan bien conocía. Era una misión a la que se sentía llamado, una vocación, un apostolado, que le llevó a la acción social en su pueblo, en la provincia, en la región, en la nación entera. Puso la llamada a la acción social cristiana por delante de sus riquezas, comodidades e intereses y gastó lo mejor de su vida en lograr la mejora material y moral de los hombres del campo, empezando por los más pobres. «¿Creéis que si no fuera por amor a Cristo vendría por estos andurriales?»(Monedero Martín, 2003, p. 153).

\section{PATRIMONIO CULTURAL Y ARTÍSTICO}

Los temas del patrimonio cultural y artístico en tierras palentinas han estado, por lo general, vinculados a la Iglesia. Por eso, no resulta extraño que el historiador Manuel Revuelta se los haya encontrado cuando le salían al paso en sus idas y venidas por los caminos de la historia de la Iglesia en la diócesis de Palencia.

Si nos remontamos a temas más lejanos en el tiempo, es el teresiano el que implica a Palencia en el siglo xvI (Revuelta, 2015). Al amparo de las efemérides del quinto centenario del nacimiento de santa Teresa de Jesús, el profesor Revuelta dio a la luz el libro Las tres estancias de santa Teresa en Palencia. Como buen historiador, a la hora de narrar cuanto ocurre en torno a la fundación teresiana en la capital palentina, contextualiza el momento histórico, los avatares que acompañan a los personajes que lo protagonizan y todo aquello que es peculiar y característico desde los puntos de vista de la religiosidad, de la vida de la Iglesia, de la cultura, de la sociología, etc. 
La narración trascurre con claridad y sencillez. Así, va contando con abundancia de datos y detalles cómo fueron los pasos de la santa fundadora del Carmelo en la ciudad, sus encuentros con las personas que colaboraron para la puesta en marcha del convento, la impresión que le produjeron sus gentes (harto conocido es su apunte de que «la gente es de la mejor masa y nobleza que yo he visto» [Las Fundaciones 29, 11]), las diversas tareas que llevó a cabo. Cinco meses — del 28 de diciembre de 1580 a mayo de 1581 - estuvo Teresa de Jesús en Palencia y, como es lógico, su ocupación primera fue la de encontrar casa donde establecer el convento. Se decidió por unas casas contiguas a la ermita de la Virgen de la Calle (que entonces se encontraba en lo que hoy es la calle de San Bernardo). La segunda y la tercera estancia de la fundadora del Carmelo en tierras palentinas se produjeron con motivo de sus viajes de ida y vuelta a Burgos para fundar allí, lo que acaeció en 1582. Revuelta analiza las cartas que santa Teresa escribió en Palencia y la interesante cuenta de conciencia dirigida a quien había sido su confesor, Alonso Velázquez, a la sazón obispo de Osma. Este texto revela la profunda vida interior de la monja abulense durante sus estancias en Palencia y la enorme alegría que experimentó cuando recibió la noticia de la aprobación del Carmelo Descalzo.

Otro tema del patrimonio cultural y artístico en torno al cual podemos agrupar varios escritos del P. Revuelta es el del Camino de Santiago. Un asunto muy querido por cuanto nació el 1 de enero de 1936 en Población de Campos, por donde pasan los peregrinos del Camino Francés a la tumba del Apóstol. De ahí que recopilara en 2010 varios escritos dispersos sobre temas vinculados al Camino de Santiago, contemplado desde una perspectiva espiritual, pues fue el aliento de la fe lo que le dio sentido y permite comprender su huella a lo largo de los siglos.

El primer capítulo (Revuelta, 2010, pp. 15-29) está dedicado a Boadilla del Camino; en ese pueblo nació el P. Nicolás de Bobadilla en 1509, cofundador de la Compañía de Jesús y misionero de Europa. Ni que decir tiene que el compañero de Ignacio de Loyola, Francisco de Javier y Pedro Fabro es un buen modelo de peregrino por los caminos de Europa, nacido en un pueblecito atravesado constantemente por peregrinos que van hasta el último confín del continente, el finis terrae.

Nuestro historiador dedica a Frómista (Revuelta, 2010, pp. 31-63) unas páginas con apuntes de historia, arte, cultura y tradiciones populares y un canto al espíritu o alma del pueblo que ha ido configurando el devenir de la historia y la cultura. Pero el capítulo más interesante es aquel en el que aborda el famoso Milagro de la Sagrada Forma, un hecho de singular importancia 
acaecido en 1453 que otorgó al priorato de San Martín nueva fama y el sobrenombre de Villa del Milagro a Frómista.

Manuel Revuelta escribe también sobre el pueblo aledaño al de su nacencia, Revenga de Campos, alivio de caminantes (Revuelta, 2010, pp. 113-119). $\mathrm{Y}$ es que un pueblo tan pequeño figura en las páginas de la historia de España, ya que por él pasaron, que no peregrinaron, el emperador Carlos y, dos siglos y medio después, el político ilustrado, economista y escritor Gaspar Melchor de Jovellanos.

Población de Campos es el pueblo siguiente a Frómista en el Camino de Santiago y su ilustre hijo le dedica tres amplios capítulos del libro (Revuelta, 2010, pp. 65-112). Trata en primer lugar la historia, luego el arte y la fe y, por último, una institución que le dio renombre, como la bailía de la Orden de Malta. Y el profesor estudioso se adentra en la historia de sus orígenes y lanza una mirada sobre el pasado de su pueblo, allí donde vivieron y trabajaron sus antepasados, legaron un patrimonio artístico y espiritual, rezaron en sus iglesias y ermitas y transmitieron a las generaciones futuras el espíritu cristiano.

Población de Campos está en el Camino de Santiago, está en un alto, como un estratégico emplazamiento castrense. Desde el siglo X los peregrinos a la tumba del Apóstol pusieron a España en contacto con Europa y trajeron una corriente de cultura, arte y fe. Desde mediados del siglo XII hasta los albores del Xix el pueblo fue un señorío de la Orden de Malta y Manuel Revuelta lo desarrolla con detenimiento en varios artículos.

La historia de Población de Campos ha dejado huellas artísticas que son manifestaciones de la fe de sus gentes a lo largo de los siglos. Revuelta ha dedicado trabajos específicos, exhaustivamente documentados, a la reconstrucción en el siglo XvII de la iglesia parroquial de la Magdalena que ya existía tres siglos antes y a su retablo mayor barroco, por cierto, restaurado en 2007, tras el incendio sufrido por el templo veintidós años antes, con un donativo de la madre del jesuita historiador.

Asimismo ha abordado los mensajes de historia, arte y fe que se encierran en las pequeñas ermitas de la Virgen del Socorro y la de San Miguel. Y no es de extrañar que se animara a difundir la calidad artística del cuadro con la bellísima imagen del Ecce Homo, atribuido a Jan Provost, perteneciente a la parroquia de la Magdalena y depositado temporalmente, por razones de seguridad, en el Museo Diocesano de Palencia. Ciertamente se trata de una joya artística, que ha sido expuesta en varias muestras nacionales e internacionales y estudiada en los catálogos correspondientes.

Nos recuerda Manuel Revuelta que el obispo Enrique Almaraz animó todas las iniciativas en favor del arte religioso y buscó el apoyo de las 
autoridades civiles, trató de despertar el sentido artístico entre los sacerdotes y que el pueblo fiel conociera y estimara el legado artístico que tenían a su alrededor y que explicaba la identidad cultural y cristiana heredada de sus antepasados y ahora presente en ellos. Conviene destacar que, con motivo de la apertura al culto del templo de San Martín de Frómista, tras su restauración, ante la multitud de peregrinos de los pueblos de la comarca, hablaron sobre la fe religiosa como fuente de inspiración cristiana no sólo el obispo sino también otros oradores presentes en el acto, tanto eclesiásticos como seglares.

Nuestro historiador dedicó atención a la desamortización (Revuelta, 1979), como en el estudio de un caso significativo: la villa norteña de Aguilar de Campoo, porque tenía monasterio de religiosos, convento de monjas, iglesia colegiata, beneficios eclesiásticos y cofradía, es decir, toda la gama de bienes eclesiásticos desamortizables, en opinión de nuestro historiador. Y sabedor de la pérdida de buena parte del patrimonio artístico, estaba también al tanto de la conciencia artística recuperada. Y a ello dedicó alguno de sus escritos. Porque el arte ha gozado de gran estima en tierras palentinas; de hecho se han valorado los legados del pasado y han sido celosamente conservados, aunque no siempre esa conciencia artística adquiriera el nivel deseado.

Sin embargo, en los pontificados de aquellos relevantes obispos diocesanos que fueron Lozano Torreira y Almaraz y Santos, se produjo una verdadera estima por el arte, propiciada y alentanda por las restauraciones, las declaraciones de monumentos, los escritos de divulgación (Revuelta, 1999 y 2010, pp. 191-207).

Poco a poco se fue creando una conciencia artística que, tras lamentar pérdidas por robos, traslados y despojos, permitía apreciar los valores culturales del pasado, respetar el legado de su historia y mostarlo con orgullo a la sociedad. Y así llegamos a tiempos recientes donde ya, situándonos en los últimos cincuenta años, se produce el resurgir de numerosas iniciativas, como las restauraciones de pintura, escultura, monumentos, edificios, la fundación de museos parroquiales y diocesanos, numerosas publicaciones científicas, exposiciones.

\section{CONCLUSIONES}

1. La investigación del jesuita Manuel Revuelta en multitud de archivos para buscar las raíces de su querida tierra e Iglesia palentina lo llevó a no 
olvidar la perspectiva espiritual de la historia y de las huellas culturales y artísticas que generó y que definen el alma de un pueblo.

2. Encontró los vestigios que ha ido dejando la fe en la vida de los hombres de aquellas tierras y supo aportar las claves necesarias para entender los contenidos tan atrayentes y significativos de la historia y sus aportaciones al mundo de la cultura.

3. Es sabido que la objetividad de los hechos narrados precisa de un cierto distanciamiento, pero en sus trabajos siempre aparece la implicación subyacente de nuestro autor.

4. Sin embargo, no hizo una historia ideologizada, como a veces se hace, con desenfoques intencionados y manipulaciones de todo tipo. Por el contrario, lleva a cabo un acercamiento sereno a los acontecimientos históricos, sin apasionamiento, con gran objetividad e imparcialidad, neutral y alejado de polémicas y simplismos distorsionadores, pero no exento de solidez y juicio crítico.

5. Deja que el lector se forme su propio juicio una vez que le ha proporcionado todos los datos sin adulación y sin sectarismo.

6. Y con gran claridad expositiva y adecuada metodología hace un relato fluido de los hechos, contextualiza las causas y las circunstancias que los rodearon, plantea con abundante aparato crítico las distintas opiniones que se han dado y emite un juicio argumentado, breve y contundente con las conclusiones que se proyectan en la vida social y eclesiástica.

\section{REFERENCIAS}

Monedero, A. (1921). La Confederación Nacional Católico Agraria en 1920: Su espíritu, su organización, su porvenir, Madrid: V. Rico.

Monedero, A. (2003). Siete años de propaganda. Crónicas de "Juan Hidalgo». Palencia: Institución Tello Téllez de Meneses.

Revuelta, M. (1979). La desamortización eclesiástica en Aguilar de Campoo. PITTM, 43, 173-208.

Revuelta, M. (1984). Un siglo de crisis y restauración en la Iglesia palentina. En J. González (Dir.), (19953). Historia de Palencia, t. II (pp. 223-233). Palencia: Diputación Provincial de Palencia.

Revuelta, M. (1987). Informes del obispo de Palencia, Don Juan Lozano, a la Santa Sede sobre el estado de la diócesis. Actas del I Congreso de historia de Palencia. t. III, vol. I. (pp. 457-472). Palencia: Diputación Provincial de Palencia.

Revuelta, M. (1990). La diócesis de Palencia durante el pontificado de Don Enrique Almaraz (1893-1907). Actas del II Congreso de historia de Palencia. t. III, vol. II. (pp. 605-650). Palencia: Diputación Provincial de Palencia. 
Revuelta, M. (1992) Origen, ocaso y renovación de los conventos palentinos. PITTM, 63, 47-84.

Revuelta, M. (1995). Iglesia y sociedad en Palencia durante el reinado de Alfonso XIII. Actas del III Congreso de historia de Palencia. t. III. (pp. 323-385). Palencia: Diputación Provincial de Palencia.

Revuelta, M. (1999). La recuperación de la conciencia artística en Palencia. PITTM, $70,359-384$.

Revuelta, M. (2008). Aspectos religiosos de la guerra de la Independencia y sus repercusiones en Palencia. Publicaciones de la Institución Tello Téllez de Meneses (en adelante PITTM), 79, 155-178.

Revuelta, M. (2010). Historia y espíritu en tierras palentinas: Camino de Santiago y otros afanes. Palencia: Institución Tello Téllez de Meneses.

Revuelta, M. (2015). Las tres estancias de santa Teresa en Palencia. Palencia: Institución Tello Téllez de Meneses. 